\title{
La "Fiesta Internacional" iniciada por la Reina Isabel de Aragón*
}

La llegada del Quinto Centenario del descubrimiento de América ha sido motivo para rememorar y, a la vez, analizar de nuevo la aportación cultural de la Península Ibérica al Nuevo Mundo. En las últimas décadas numerosas editoriales y revistas especializadas han publicado centenares de estudios en los que se han destacado tanto los aspectos históricos como los literarios, sociales, folklóricos, etc. de esta contribución ibérica.

Por una parte, se destaca que los misioneros de la Península Ibérica trajeron numerosas fiestas y celebraciones cristianas a las Américas y, por otra, el hecho de que el rito y las formas de estas celebraciones religiosas se mezclaron con manifestaciones propias del indio americano y del negro.

A partir de la época colonial y ya entrado el siglo XIX, la influencia indígena americana afectó cada vez menos las nuevas celebraciones religiosas importadas de allende los mares debido a que el objetivo de estas fiestas era mantener las tradiciones del emigrante español o portugués, más que la evangelización del indio. Así se produjo la incorporación de la Fiesta del Espíritu Santo al folklore americano.

Esta fiesta se originó de una tradición cuya protagonista era Santa Isabel de Aragón (1271-1336), esposa de D. Dionís de Portugal, reina conocida por su caridad hacia los pobres. Según la tradición, la reina, por inspiración divina, ordenó la construcción de la iglesia del Espíritu Santo en Alenquer, Portugal, mediante lo cual se inició el culto a la tercera persona de la Trinidad ${ }^{1}$. Según el obispo de Porto, D. Fernando Correia de Lacerda:

* Deseamos agradecer a los Dres. Jordi Piqué Angordans, Adalino Cabral y Geoffrey L. Gomes que nos ayudaron con este estudio.

1 Los historiadores Manuel de Esperança, História Seráfica dos Frades da Ordem de S. Francisco em Portugal (Lisboa, 1656), I, pp. 130-33; Rodrigo da CunHA, História Eclesiástica da Igreja de Lisboa (Lisboa, 1642), fol. 122; Francisco Brandão, Sexta parte da Monarquia Lusitana (Lisboa, 1672), pp. 184-85, indican que Isabel de Aragón y Don Dionís establecieron la fiesta en el siglo XIV. Otra fuente, Guilherme José Carlos Henriques, Alemquer e Seu Concelho (Alenquer, 1901), propone a la Orden Franciscana como iniciadora de esta fiesta, con el apoyo de la reina Isabel de Aragón. A pesar de esta fuente, todos los estudios que consultamos aceptan la tradición de que Isabel de Aragón inició esta fiesta. 
Durante la Pascua Florida, el hombre que representa al emperador va con todos los honores a la iglesia de San Francisco, acompañado de la nobleza y del pueblo. Lleva consigo a dos hombres, que representan a los reyes, y a tres pajes con una corona cada uno, «una de las cuales fue cedida por la reina santa [Isabel] para este acto». Al llegar al altar hacen la ofrenda de las coronas a Dios. Un sacerdote con hábito talar coloca las coronas en la cabeza del emperador y de los reyes. De allí todos van en procesión ${ }^{2}$.

Por la tarde se repite la coronación en la misma iglesia. Después de los bailes y de la distribución de ramilletes y de ofrendas, el emperador vuelve a la iglesia del Espíritu Santo donde ofrece la corona al altar y es coronado de nuevo por un sacerdote.

Esta fiesta imperial, llamada popularmente «império», sigue celebrándose todos los domingos hasta Pentecostés, en cuya víspera el emperador sale de la misma iglesia con un hombre que lleva dos manojos de velas, uno de los cuales se deja en el altar de esta iglesia y el otro en el altar de otra, donde arde todo el año. La procesión continúa hasta la iglesia del Espíritu Santo, donde se bendicen el pan y la carne, alimentos que otro día serán distribuidos entre los pobres ${ }^{3}$.

Según el antropólogo Emilio Willems, la fiesta del Espíritu Santo se celebraba por todo Portugal hasta el siglo XVI, pero ya en la segunda mitad del XVII sólo se practicaba el rito de la coronación del emperador en una pequeña parte de Portugal ${ }^{4}$. A finales del siglo XIX, la fiesta del Espíritu Santo se celebraba en las márgenes del río Zézere, o sea entre Cambas y Guarda, y en otros lugares de Portugal's. En el presente siglo, el culto ha seguido practicándose en algunos sectores rurales y hoy día sólo quedan

2 Luís Chaves, "A tradição nacional da 'Rainya Santa'», Revista de História, XII (1923), pp. 49-50. En otros estudios más recientes se explica el papel de Isabel de Aragón como iniciadora de esta fiesta: Mary Lyn SALVADOR, «Food for the Holy Ghost: Ritual Exchange in Azorean Festivals», Time Out of Time: Essays on the Festival, ed. Alessandro Falassi (Albuquerque, New Mexico, 1987), pp. 247-49.

3 Ribeiro Guimaraes presenta una variante de esta historia en Summario de varia bistória (Lisboa, 1872), I, 222.

4 Emilio Willems, «Acculturative Aspects of the Feast of the Holy Ghost in Brazil», American Antbropologist, 51 (1949), 403-44. Al contrario, el Couseiro, manuscrito del siglo XVI, menciona que en el siglo XVI sólo Alenquer y Leiria celebraban esta fiesta (Angelo Ribeiro, "Assistência e Cultura», História de Portugal, ed. Damião Peres [Barcelos, 1932], pp. 473-74).

5 Teófilo BRAGA, $O$ povo portuguez nos seus costumes, creenças e tradições (Lisboa, 1986), II, 202. Joyce C. Riegelhaupt, «Festas and Padres: the Organization of Religious Action in the Portuguese Parish». American Antbropologist, LXXXV (1973), p. 840, indica que en la villa peninsular de São Miguel, la Fiesta del Espíritu Santo se celebraba en $1889 \sin$ procesión. 
algunas reminiscencias de este rito en Tomar ${ }^{6}$. Sin embargo, esta tradición se reinició debido a un hecho histórico importante: la expansión occidental portuguesa. Así pues, a partir del siglo XV, la fiesta fue trasladándose poco a poco, a través del Océano Atlántico, hacia el Nuevo Mundo.

Cuando Portugal descubrió las Islas Azores, sus primeros pobladores, sobre todo los gobernadores (capitões donatários), introdujeron este culto en las islas, tradición que se vio reforzada durante los siglos XVI y XVII debido a numerosas promesas hechas al Espíritu Santo para terminar con la peste, el hambre y las erupciones volcánicas que amenazaban las islas ? En Santa María, la primera isla azoreana descubierta, la misa del Espíritu Santo se celebró ya a mediados del siglo XV. En la isla Terceira João Vas Corte-Real, capitão donatário de Angra, instituyó la hermandad del Espíritu Santo en Angra en 1474. Otro documento indica que Manuel I otorgó una hermandad en Angra (1508) y que en este mismo año se celebró Pentecostés con fiesta en esta ciudad ${ }^{8}$. De esta manera la fiesta se extendió a las nueve islas de este archipiélago portugués y llegó a ser la más grande y popular de las fiestas azoreanas.

A causa de los problemas económicos con que los habitantes de las Azores se han tenido que enfrentar y la ubicación de sus islas, en medio del Atlántico entre Europa y las Américas, la emigración fue inevitable, y desde tiempos coloniales se dirigió hacia el Nuevo Mundo. Esta emigración al continente americano se incrementó en el siglo XIX y, sobre todo, desde principios del XX. Durante estos movimientos migratorios los habitantes de las Azores llevaron su Fiesta del Espíritu Santo al Brasil, a las Bermudas, a los Estados Unidos de América y al Canadá. Hoy día la fiesta se celebra en las Azores con el mismo vigor que tiempos atrás; sin embargo, con su paso a las Américas, sus preparativos y organización, así como la propia celebración, han sufrido algunas modificaciones.

6 Jaime DiAs LOPES, Ethnografia de Beira, lendas, costumes e superstições (Lisboa, 1944), pp. 86-87; véase también BRAGA, II, 206. Sobre las reminiscencias de esta fiesta en el norte de Portugal, véase Flávio Gonçalves, «Procissão de Mordomos», DouroLitoral, 5.: serie (1952), pp. 80-88; según Rodney GAllop, Portugal; A Book of FolkWays (Cambridge, 1936), p. 104, la fiesta sobrevivió en Alcabideche, cerca de Cascais, hasta 1911.

7 Braga, II, 202; Leo Pap, The Portuguese Americans (Boston, 1981), p. 193; Onésimo T. AlmeIDA, "A Profile of the Azorean», Issues in Portuguese Bilingual Education (Cambridge, Massachusetts, 1980), p. 160; según Francis M. ROGERS, Atlantic Islanders of the Azores and Madeiras (Quincy, Massachusets, 1979), p. 300, los flamencos que emigraron a las Azores promovieron la fiesta por su propio entusiasmo y por la devoción de los duques de Burgundia al Espíritu Santo.

8 Francisco Carreiro da COSTA, «As Festas do Espírito Santo nos Açores», Insulana 13 (1957), 5-6; Gervásio Lima, Festas do Espirito Santo (Angra do Heroismo, 1932), pp. 19-21. 
Generalmente, en las Azores las hermandades preparan la fiesta a lo largo de todo el año: recogen dinero con el que posteriormente compran ganado y grano para alimentarlo, y además contratan músicos para amenizar las fiestas. Organizan las distintas actividades con la gente del pueblo, a la que asignan diversas responsabilidades que deben llevar a cabo el día de la celebración. El jueves antes de la fiesta la gente engalana el ganado con lazos y flores y se pasea por las calles acompañados de la junta organizadora, una banda y un grupo de cantantes.

La organización actual, según se celebra en las Azores, dista algo de la que se estableció en la ciudad brasileña de Cunha, estado de São Paulo, en parte porque fueron colonizadores de Portugal los que fundaron la fiesta en Cunha: en el otoño, después de la caída de las primeras lluvias, un grupo de jóvenes (la «folia»), encabezado por un agricultor rico, recorre varias granjas con un grupo de músicos. Tocan música para la familia campesina a cambio de ofrendas de maíz, judías, así como algún animal de corral (cerdos, gallinas o becerros). Desde allí se desplazan a otra granja, donde pasan la noche, siempre llevando el estandarte encarnado del Espíritu Santo, donde figura una paloma en su parte superior y con el que bendicen a la familia del labrador. A cambio de esta bendición el granjero ofrece una espléndida comida a la «folia» y organiza un baile en su honor?

En épocas anteriores la «folia» era una parte esencial del rito en honor al Espíritu Santo, tanto en Portugal como en las Azores y en Brasil. Formaba parte de este grupo, denominado «foliões», un cantor o maestro de la «folia», músicos que tocaban tambores, pandero y címbalos, y un abanderado con la bandera del Paráclito ${ }^{10}$. El maestro de la «folia» cantaba melodías a la puerta del labrador, algunas de las cuales todavía se con-

9 Bracia, II, 203. En el nordeste de Portugal la «folia» salía de la iglesia todos los domingos de Pascua hasta Pentecostés por las calles de los pueblos. Durante tres de estos domingos, uno de los «mordomos» (mayordomos) organizaba una comida para sus parientes, costumbre muy similar a la de las «funções» de las Azores, según documenta Patricia W. Vaurie, "Festival in the Azores», Commonweal (27 de mayo de 1938), p. 126.

10 En el Brasil un violinista actuaba como solista: Afonso A. Freitas, «Folia do Espírito Santo». Revista do Instituto Histórico e Geográfico de São Paulo, 23 (1925), p. 121. En Río de Janeiro existía la «folia» desde principios del siglo XIX, la cual constaba de un grupo de muchachos de nueve a once años que iban vestidos de pastores y llevaban instrumentos pastoriles (a veces uno tocaba una guitarra pequeña, llamada «machete»). Les seguían los «barberos», que interpretaban piezas musicales, y a continuación los miembros de la hermandad, que llevaban banderas y emblemas y recolectaban limosnas. Esta costumbre dejó de existir en Río de Janeiro a mediados del siglo xIX: Manuel Antônio de Almeida, Memórias de um sargento de milícia (Rio de Janeiro, 1969), pp. 188-89. 
servan ${ }^{11}$. Por desgracia, la «folia» ha sufrido algunas modificaciones, e incluso ha desaparecido en algunas partes, mientras que los músicos han sido sustituidos por una banda, tanto en Brasil como en algunas islas de las Azores (Terceira, Pico) y en el continente norteamericano. Sin embargo, en las Azores y en los Estados Unidos de América (East Providence, Rhode Island) empieza a reaparecer la «folia».

En lo que se refiere a la «altura do Espírito Santo», que todavía se mantiene en las Azores, se trata de una tradición en la cual, durante las ocho semanas desde Pascua hasta Pentecostés, un «emperador» de cada pueblo es «coronado» ${ }^{12}$. Este rito (llamado «função»), que tiene lugar en una casa particular, incluye dar de comer a los pobres y organizar una comida en comunidad. Para esta comida se compra vino y se preparan tres clases de pan: pan de agua (o de los inocentes), que se come con la sopa o se da a los niños después de la «coronación»; pan de leche, que se come con el segundo plato; massa sovada, que suele ser dulce y que se sirve a los pobres y al final de la comida comunal. Matan dos o tres vacas y distribuyen carne cruda a los huéspedes y lo demás lo cocinan para los pobres. A veces también cuecen la carne con legumbres para la comida en común ${ }^{13}$. Antes de la comida los fieles van en procesión a la iglesia para la coronación. De allí el grupo vuelve en procesión a la casa del «emperador», lo cual es indicativo, según los vecinos del lugar, de la unión existente entre el pueblo y el Espíritu Santo. Después de la comida se entregan las limosnas a los pobres. Al atardecer la corona se lleva a casa de otro «emperador» donde se iza el estandarte adornado con flores para indicar que «el Espíritu Santo habita en esa casa».

Al llegar al continente americano, la Fiesta del Espíritu Santo se celebró por primera vez en San Leandro, California (1882) ${ }^{14}$, aunque habiendo su-

11 Freitas, op. cit., pp. 121-29; Teófilo Braga, «As festas do Espírito Santo», Açores (Lisboa, 1964), pp. 80-82.

12 Según Francis M. Rogers, la tradición de la coronación del emperador y de personajes reales se reforzó por el recuerdo de la coronación de Doña Leonor de Portugal y del emperador Federico III en 1452, época en que empezó la emigración de Portugal a las Azores: "Portuguese», Harvard Encyclopedia of American Ethnic Groups (Cambridge, Massachusetts, 1980), p. 816. La «função» no se ha conservado en América del Norte.

13 La cocinan con distintas legumbres: véase Mari Lyn SALVADOR, «Altura do Espírito Santo», Museum of California (marzo-abril de 1981), pp. 8-10.

14 Eduardo M. Dias, «O Culto do Espírito Santo entre os emigrantes portugueses na Califórnia», Encruzilhada/Crossroads: First Symposium on Portuguese Traditions (Los Angeles, 1980), I, p. 49. Hay tres zonas principales de inmigración portuguesa en los Estados Unidos: California, Hawai y el Nordeste. En esta última zona, donde viven el 60 por 100 de los inmigrantes, se celebró por primera vez la fiesta del Espíritu Santo en Gloucester, en el Estado de Massachusetts, en 1902 (PAP, op. cit., p. 194). Las fiestas 
frido algunas modificaciones. A un nivel menor, en 1871, Rosa Pedro (Rose Brown), inmigrante de Corvo (Azores), trajo la corona de plata del Espíritu Santo a Half Moon Bay, California, donde invitó a otros inmigrantes portugeses a su casa a adorar la corona y pasar las noches cantando y bailando ${ }^{15}$. Esta celebración significa la introducción de esta fiesta portuguesa en Norteamérica. En las iglesias católicas de los Estados Unidos fundadas por sacerdotes e inmigrantes portugueses, se celebra la fiesta durante un fin de semana después de Pentecostés, a finales de septiembre. Las hermandades o comités de parroquianos tratan de escoger una fecha que no coincida con la de otra iglesia o parroquia cercana, de manera que los fieles puedan asistir, no sólo a su propia fiesta, sino a la de las iglesias contiguas. Asimismo, los sacerdotes de otras parroquias con frecuencia ayudan en la misa, que suele celebrarse en forma de oficio solemne, con presbítero, diácono y subdiácono, e incluso hoy día se concelebra una misa, según costumbre eclesial postconciliar.

En los Estados Unidos, evidentemente, el culto ha variado de un lugar a otro, pero generalmente se siguen las prácticas que imperaban en las zonas urbanas de las Azores, donde el sacerdote, durante la misa, coronaba a unas jóvenes, en vez de a un «emperador» ${ }^{16}$. En Norteamérica es tradicional que el sacerdote corone sólo a una joven (la reina o emperatriz de la fiesta) escogida por el comité de parroquianos o hermandad. Esta joven va en procesión a la iglesia con dos grupos, uno de niños y niñas y otro de chicas (damas o «aias»), todas ellas vestidas de blanco. En otras palabras, las dos funciones que tenía asignadas el «emperador», como organizador de la fiesta y soberano coronado, se han perdido en Estados Unidos, donde

de California no influyeron en la creación de las de Gloucester, aunque ambas son de origen azoreano. En Gloucester, José P. Mesquita, capitán de un barco de pesca, votó que celebrarían la fiesta del Espíritu Santo si se salvaba su barco de una tempestad invernal. Salvados él y su tripulación, Mesquita pidió la corona de las Azores e inició la fiesta en esta ciudad, cuyos habitantes portugueses eran pescadores azoreanos, sobre todo de Santa María y Pico. En el Canadá actual, se celebra en varias ciudades, como en Québec: João António AlPalhño y Victor Manuel Pereira DA Rosa, Les Portugais du Québec (Ottawa, 1979), p. 220. Según José Ferreira Moreno, «llhas Canecas», Portuguese Times (25 de julio de 1991), 4, una hermandad del Espíritu Santo fue organizada en Hawai en 1891. La fiesta se celebró incluso en Macao.

15 PAP, op. cit., p. 193; «Irmandade do Espírito Santo», Holy Ghost Festival Centennial Year 1871-1971 (Half Moon Bay, 1971), p. 12.

${ }^{16}$ En las zonas rurales el emperador es coronado en la fiesta de Pentecostés y en el domingo fiesta de la Santísima Trinidad. 
este papel es adoptado por uno o dos «mordomos» (mayordomos), quienes además tienen la misión de organizar la fiesta ${ }^{17}$.

En las Azores se conserva un pequeño edificio, de arquitectura sencilla, llamado el «Império do Divino» («teatro», en São Miguel; «alpendres», en Santa Maria), el cual, mediante el pago de una cuota, es utilizado por la Hermandad del Espíritu Santo para guardar durante el año todos los útiles pertenecientes a la fiesta (coronas, banderas, estandartes, pendones, báculos y utensilios varios para la comida). Sólo en Terceira hay más de cincuenta y cinco «Impérios». Durante la fiesta, el «Império» se convierte en el foco religioso principal: en un altar decorado con flores rojas y blancas y papel rizado de colores colocan la corona y el cetro del Espíritu Santo. Los fieles dejan allí sus óbolos, con lo cual podrán adquirir comida y toda clase de objetos, que serán consumidos y/o utilizados durante la fiesta. El «Império» sigue en vigor en algunos lugares del Brasil y en alguna ciudad de California, como San Diego ${ }^{18}$. En el nordeste de los Estados Unidos, así como en Canadá, es costumbre más común erigir un altar para la corona en el salón de la hermandad o en la misma iglesia.

Aparte de los numerosos preparativos para la fiesta, entre los que hay que destacar la iluminación con todo tipo de bombillas para decorar el «Império», durante la semana anterior al domingo en que se celebra la fiesta se llevan a cabo diversas actividades: en primer lugar, se celebra una «novena» por las noches y a veces ante el «Império»; otra actividad importante se desarrolla en el «arraial», un paseo o plaza (a veces la misma calle e incluso la iglesia), donde tiene lugar la fiesta y donde toca la banda. Cabe señalar también la «bezerrada», o desfile del ganado adornado con flores y papel rizado y la posterior distribución de la carne; el «pezinho», que son canciones que se cantan en competición para honrar a los que ayudan en la fiesta y que tiene lugar durante la «bezerrada».

De estas actividades, la ornamentación con luces y la costumbre de contratar una banda de música han llegado a ser las más arraigadas tanto en los Estados Unidos como en el Brasil. Asimismo, en algunas parroquias se ha mantenido la «novena», pero es menos frecuente que en épocas pasadas ${ }^{19}$. Por otra parte, se puede también admirar la «bezerrada», e incluso un desfile de carros decorados y tirados por bueyes («carro de toldo»), en algunas zonas rurales, como en Hudson, Massachusetts, aunque es ésta una tradición muy poco

17 Según Willems, op. cit., p. 405, sólo hay un «emperador» en Cunha (Brasil), el cual contribuye a la fiesta con dinero y es el organizador principal. En las Azores los señores de la fiesta se llaman «mordomos» o emperadores.

18 Mari Lyn Salvador, Festas Açoreanas:Portuguese Religious Celebrations in California and the Azores (Oakland, 1981), pp. 52-53. En Rio de Janeiro el «Império» ha dejado de celebrarse (Manuel Antônio de ALmEIDA, op. cit., p. 193).

19 Willems, op. cit., p. 402; Manuel Antônio de AlmeidA, p. 189. 
común ${ }^{20}$, al igual que el «pezinho», que se ha conservado en algún lugar de California ${ }^{21}$. En el continente norteamericano las fiestas «do Divino» tienen lugar, por lo general, en el salón o recinto (también llamado «arraial») de la hermandad, en el club fraternal de inmigrantes portugueses, o en la misma iglesia. Las bandas de música amenizan estas reuniones, se recogen donaciones, se vende comida y también se proporcionan actividades recreativas y juegos para los niños.

El domingo por la mañana se acostumbra organizar una procesión que se inicia en el «Império» o en casa de un devoto donde se encuentra la corona del Espíritu Santo. Por lo general la procesión está constituida por unas jóvenes que llevan la bandera encarnada, la reina y sus damas de honor, el sacerdote y monaguillos y, a veces, los socios del comité de la fiesta o la hermandad, el «mordomo»y su familia, y la/s banda/s ${ }^{22}$. Es precisamente en la procesión donde han entrado en esta fiesta portuguesa elementos religiosos y profanos de la cultura norteamericana, con muchos tintes patriótico-militares: por una parte, los Caballeros de Colón (una orden católica de laicos), la guardia de honor de la bandera, grupos de músicos con tambores y trompetas, un grupo de instrucción militar, la bandera estadounidense junto a la portuguesa, así como un grupo de soldados jubilados, conocidos como la Legión Americana ${ }^{23}$.

Después de la misa y la coronación de la reina, la procesión pasa al «arraial», donde se celebra la comida en comunidad en la que participan hasta tres mil comensales ${ }^{24}$. En la comida, que es gratis para los participantes en

20 Adalino CABral, «Festa Açoriana en Hudson (E.U.A.). Impérios Marienses», $O$ Imigrante (19) de agosto de 1983), p. 3.

2 Eduardo M. Dias, op. cit., p. 49; Salvador, Portuguese Religious Celebrations in California and the Azores, p. 79.

2.2 A veces algunos representantes municipales, como el alcalde o los concejales, aunque no sean de origen portugués, participan también en la procesión. En las Azores, los concejales («veradores»), con varas del «mordomo», también figuran en la procesión.

23 Eduardo M. Dias, op. cit., p. 49.

$\therefore$ En las Azores, después de la misa y de la coronación, se celebran los «bodos», es decir, la ofrenda de pan y vino a los pobres, cuyo origen, según Angelo RiBEIRo, op. cit., p. 473, podría ser los panis gradilis de los romanos. La palabra «bodo» o «vodo» tiene, no obstante, un significado más amplio: se refiere a la misma fiesta, con la preparación semanal y la comida en comunidad, organizada por la hermandad o por los parroquianos, todo ello en un sentido mucho más amplio que la «função» propiamente dicha. Tiene lugar únicamente durante la séptima y octava semanas después de Pascua. La ofrenda de pan y vino, e incluso de leche y queso, costumbre muy enraizada en Brasil, California y Hawai, se ha ido perdiendo paulatinamente debido a diversos factores económicos (WILLEMS, op. cit., pP. 407-8), así como a la implantación de una asistencia pública para los pobres (PAP, op. cit., p. 196). 
la fiesta, se sirve una sopa «do Espírito Santo», cocida a base de carne, pan y repollo ${ }^{25}$; luego también se sirve la «massa sovada». Al final de la comida se ofrecen a los presentes unos bollos hechos con este pan y otros regalos. Por la tarde hay un baile en el salón, en el que se puede bailar al son de la «chamarrita», danza típica de las Azores, así como de los bailes típicos del país adoptivo, costumbre muy arraigada en California ${ }^{26}$.

En el Este de los Estados Unidos, donde hay muchos emigrantes de la isla más grande de las Azores, São Miguel, se da más importancia a la tradición de las «domingas» que a ninguna otra relacionada con la fiesta en cuestión. En lugar de colocar la corona del Espíritu Santo en el «Império», el «mordomo» guarda la corona en su casa durante el año, excepto en las semanas entre Pascua y Pentecostés, en que va de casa en casa de las distintas familias, que son seleccionadas cada año por sorteo, al igual que el «mordomo». Los que no consiguen una «dominga», es decir, haber tenido el honor de albergar la corona en su casa una semana, están obligados a contribuir con comida y otros donativos para el fin de fiesta del año siguiente.

Hay, evidentemente, otras actividades que tienen o tuvieron lugar en las fiestas del Espíritu Santo en las Américas. En el Brasil, por ejemplo, los «moçambiqueiros» toman parte en representaciones teatrales que terminaban con la conquista de los moros. La corrida de toros también formaba parte de la fiesta, aunque hoy se ha convertido en fuegos artificiales o en una bufonada ${ }^{27}$. En la ciudad de Artesia, California, se construyó una plaza de toros, pero sólo se podía usar como parte integrante de un festival religioso, según rezaban las ordenanzas municipales ${ }^{28}$. Y tanto en el Brasil como en los Estados Unidos las subastas se realizan la semana antes del domingo de la fiesta o durante la misma fiesta ${ }^{29}$.

Hay varios elementos de cohesión de la fiesta en las variantes de las Azores, Brasil, Estados Unidos de América y Canadá: la colección de do-

${ }^{25}$ Esta sopa puede contener, asimismo, pescado. En el Este de los Estados Unidos también es costumbre servir un caldo hecho con huevos, pedazos de pan y yerbabuena. La carne, una vez hervida en el caldo, se sirve por separado.

26 El sábado por la noche también se celebra un baile, costumbre común en el Brasil (Cunha) y en California (San José). Cada vez que llevaban la corona a casa del nuevo emperador o «mordomo», era costumbre organizar, asimismo, un castillo de fuegos artificiales tanto en el Brasil como en las Azores.

27 WILLEMS, op. cit., p. 403.

- 28 Eduardo M. DiAS, op. cit., pp. 49, 52. Esta tradición proviene, en parte, de la «tourada a corda» de la isla Terceira de las Azores, en cierto sentido semejante a los «sanfermines» de Pamplona.

29 William F. Stadelman, Glories of the Holy Ghost (Techy, Illinois, 1919), p. 94. 
nativos por las hermandades o parroquias; la corona de plata, cetro y «bandeira» encarnada (blanca en algunas islas occidentales azoreanas); el concierto de música de la banda; la procesión a la iglesia; la coronación del emperador (Azores), un muchacho o una joven que representa la reina Isabel; el «bodo» y la subasta. Sin embargo, cada sitio que celebra esta fiesta sigue un programa distinto. Hay algunas variedades en la manera de celebrarla entre las nueve islas azoreanas, aunque las villas y ciudades siguen prácticas comunes entre sí mismas. Entre los elementos únicos, las monjas de Horta (isla de Fayal) festejaban en los conventos, guardando la costumbre de la coronación y el ofrecimiento de dulces a los convidados ${ }^{30}$. En la isla de São Jorge el «bando» recita loas con intención anecdótica o satírica. Según Francisco Carreiro da Costa:

O bando, cuja origem desconhecemos, tem qualquer coisa de Cervantes, pois quem o recita é um personagem bem falante, vestido de claro, montando vistoso cavalo e que lembre a figura de Quixote. Acompanha-o sempre um velho andrajoso -o velho do bando- montado num burro, como Sancho Pança e que comenta com chiste todas as quadras recitadas pelo outro personagem ${ }^{31}$.

Para dar mejor idea de la fiesta, comparamos aquí dos programas, uno de la capital azoreana, Ponta Delgada, y otro de la ciudad californiana de San Leandro. En ambos lugares rezan el rosario el jueves, viernes y sábado por la noche. En Ponta Delgada anuncian la fiesta el jueves por la tarde con un montero ${ }^{32}$. A continuación hacen un desfile de ganado y, por la tarde, la puesta de luces, el concierto por la banda de música y bailes de grupos folklóricos. El viernes por la noche bendicen la corona y bandera del Espíritu Santo, hacen una procesión y abren las despensas. Luego hay concierto de música y bailes folklóricos en el «arraial». El sábado por la tarde almuerzan sopas del Espíritu Santo, seguido por un desfile en que entran las «folias», carros de bueyes y grupos o conjuntos típicos de cada barrio. Éstos y las «folias» hacen concursos por la noche. A la medianoche tiran fuegos artificiales. El domingo por la mañana hay un «bodo» (desayuno de leche y panes) para los niños. A las dos de la tarde la coronación tiene lugar y luego forman otra procesión. Por la noche subastan ganado y otras ofrendas y entregan premios a los mejores grupos de «folias», baile folklórico y concursos de carro y juntas de bueyes.

En California, tradicionalmente el sábado al anochecer, la reina, acompañada por su séquito, llevaba la corona a la capilla, donde la esperaban

30 Carreiro da Costa, op. cit., p. 40.

31 Carreiro da Costa, op. cit.,p. 29.

32 «Grande Festa do Espírito Santo», Atlantic Express (julio de 1988), p. 28. 
la comisión de la fiesta y la banda de música, que toca por la noche ${ }^{33}$. En San Leandro, el «bodo» de leche y pan se celebra al mediodía, y por la tarde cantan canciones populares, distribuyen comida y refrescos y bailan los grupos folklóricos. Por la noche hay la «cantoria» en el salón de la iglesia ${ }^{34}$. Es tradicional en varias ciudades californianas (por ejemplo, San José y Santa Cruz) bailar la «chamarrita» y bailes norteamericanos el sábado por la noche, mientras los fuegos artificiales no son tan comunes como en los años pasados. El domingo de la fiesta se comienza con la procesión a la iglesia donde los sacerdotes celebran una misa al mediodía. Después de la misa, hay el gran almuerzo de sopa y carne en que todos participaban en tiempos pretéritos. Hoy día en San Leandro sólo los que llevan billete pueden asistir debido a la falta de espacio. Por la tarde, la subasta.

A modo de conclusión podríamos destacar que, por regla general, la forma adoptada por la Fiesta del Espíritu Santo está supeditada principalmente a las costumbres del grupo dominante de población inmigrada. Así, por ejemplo, en el Brasil -excepto en la provincia de Minas Gerais, donde muchos son originarios de las Azores- se mantienen prácticas comunes en Portugal y en la isla de Terceira. Sin embargo, en California, donde la inmigración proviene principalmente de las islas occidentales de las Azores, predominan las costumbres de islas como São Jorge, Graciosa y Terceira. Por esta razón se pueden documentar, tanto en California como en el Brasil, costumbres como un «concurso de canciones» o una corrida de toros («tourado a corda») ${ }^{35}$. En el este del país predominan costumbres como las «domingas», procedentes de las islas orientales de las Azores, como São Miguel y Santa Maria, aunque este sistema de sorteo existe también en Terceira.

Los elementos de la fiesta, sus ritos, cultos y prácticas, son en su conjunto variados y múltiples, y sus orígenes resultan difíciles de precisar, pues se remontan al siglo XIII. Sin embargo, las modificaciones introducidas en las Américas se pueden explicar por las grandes extensiones de tierra (sobre todo en el Brasil y en el estado de California, en los Estados Unidos). En el caso del Canadá y de los Estados Unidos, debido a la cultura dominante, tanto francófona como anglosajona, también se pueden explicar debido a los diversos factores sociales y económicos. Por otra parte, al propio tiempo que los hijos, nietos o bisnietos de los inmigrantes se integran más y más

33 Anna H. Gayton, «Descrição das Festas do Espírito Santo, Feitas pelos Portugueses da Califórnia em 1947», Insulana, 4 (1948), 393.

34 «Império do Emigrante Açoriano», Jornal Portugués (25 de julio de 1991), 7.

35 Anna H. Gayton, «Luso-California Culture and Its Research Needs», Actas do Colóquio Internacional de Estudos Luso-Brasileiros (Nashville, 1953), p. 84. 
en la cultura adoptiva, van dejando poco a poco la portuguesa y sus tradiciones ${ }^{36}$. Sin embargo, también se producen modificaciones que se deben por desgracia a las disputas entre clero y hermandades, e incluso entre parroquianos.

La iglesia católica nunca sancionó por completo la Fiesta del Espíritu Santo y durante siglos ha tratado de eliminar ciertas prácticas seglares y ritos profanos, sobre todo en las Azores ${ }^{37}$. En las Américas, la clerecía de origen portugués acepta o tolera la fiesta por varios motivos: aparte de la fe demostrada por el pueblo en tales celebraciones y del hermanamiento de los parroquianos que la fiesta proporciona, también cabe señalar el beneficio económico que la fiesta representa para la parroquia. El clero, por una parte, ha intentado hacer desaparecer todo aquello que de secular, incluso seglar, pueda tener la fiesta y, por otra, mantener un cierto control sobre las donaciones. Sin embargo, ello a menudo ha conducido a encrespadas contiendas ${ }^{38}$. En el Nuevo Mundo, sin embargo, se ha mantenido la celebración de la Fiesta del Espíritu Santo, aunque sin la misa y con nula participación de la iglesia ${ }^{39}$.

La fiesta, no obstante, se ha mantenido en las Américas, reforzada por la fuerte inmigración de las Azores, tanto de los recién llegados, como de los hijos de los inmigrantes, para quienes es un alegre recuerdo de su niñez, cuando solían recibir atenciones especiales. Es curioso que los portugueses de la Península y los de las islas Cabo Verde y las Madeiras, donde no arraigó tanto la Fiesta del Espíritu Santo, son de los más activos en su participación en ella al llegar a las Américas. En este sentido, la fiesta deviene un vínculo de unión entre todos los emigrados de las distintas tierras portuguesas.

DAVID J. VIERA

Tennessee Tech. University

36. PAP, op. cit., p. 196.

37 J. A. Pereira, «Sobre as Festas do Espírito Santo. Censuras e Leis da Autoridade Diocesana desde 1560», Boletim do Instituto Histórico da Ilba Terceira (1950), 58-63.

38 WILlEMS, op. cit., p. 403.

39 PAP, op. cit., p. 197. 
Los cronistas y la tradición establecen que Isabel de Aragón inició la fiesta del Espíritu Santo en Alenquer, Portugal, en la Edad Media. Esta fiesta pasó a todo Portugal, pero hoy día se celebra en forma modificada sólo en Tomar. La expansión marítima portuguesa del s. XV llevó la fiesta a las Azores. Desde allí los azoreanos trajeron su fiesta consigo a Brasil, los Estados Unidos de América, Canadá y Bermudas, donde fue modificada por factores geográficos, sociales, económicos y culturales. Los elementos indígenas (bandera del país adoptivo, organizaciones militares y sociales que no existen en Portugal) entraron en esta fiesta, la más popular de origen portugués en América del Norte.

Franciscan chroniclers and tradition state that Isabel of Aragon established the Holy Ghost feast in Alenquer, Portugal, in the Middle Ages. The feast became widespread in Portugal to the seventeenth century, but today only Tomar celebrates a modified version of it. Fifteenth-century Portuguese maritime expansion brought the feast to the Azores. Azoreans later extended the feast during the last three centuries to Brazil, the United States of America, Canada, and Bermuda, where it was modified because of geographic, social, economic, and cultural factors. Indigenous elements (flag of the adopted nation, military and social organizations non-existent in Portugal) take part in this most popular Portuguese festival in North America. 

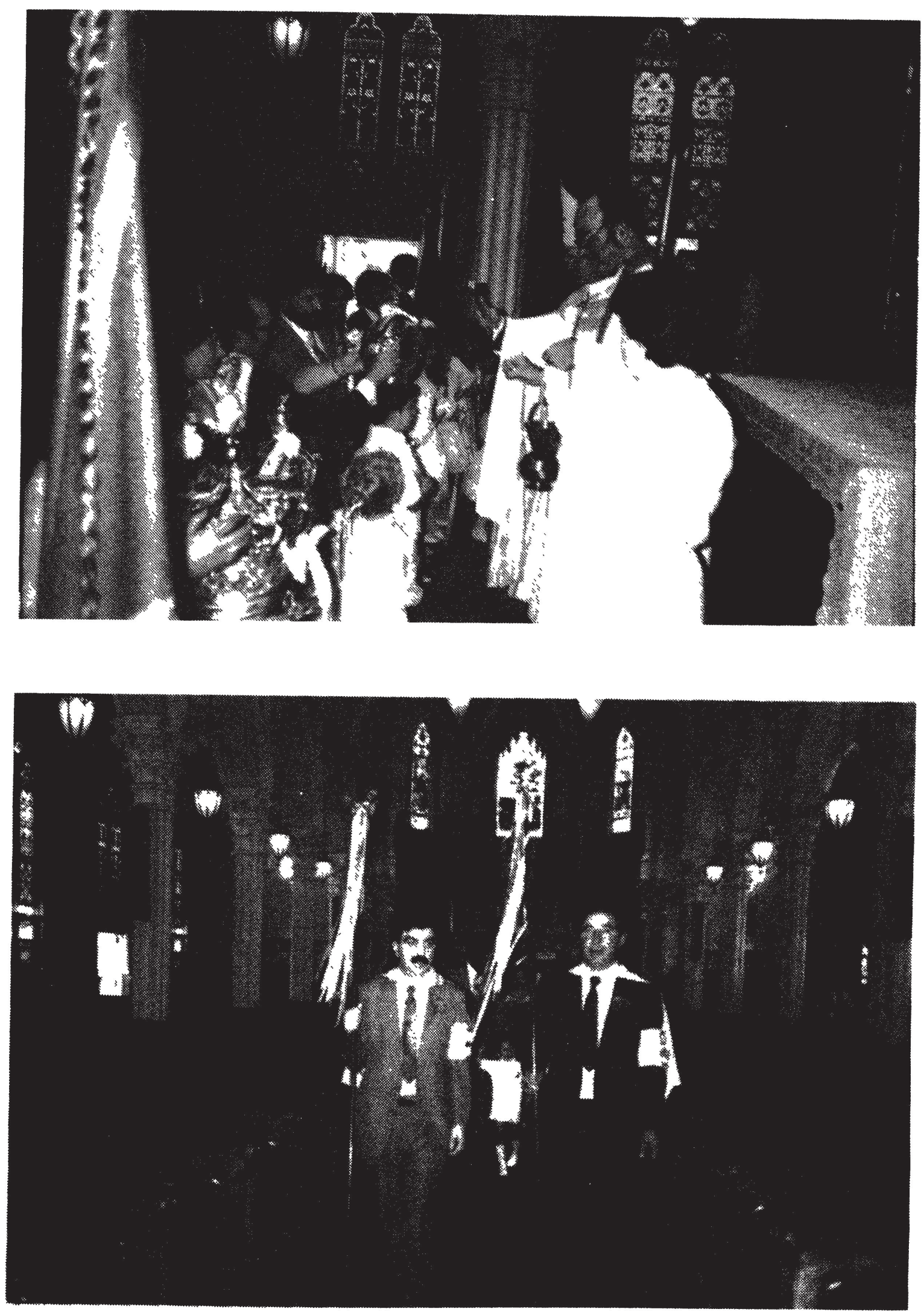

LÁM. I.-Fig. 1: Coronación de un joven (Hudson, Mass., USA). Fig. 2: La procesión saliendo de la iglesia. 

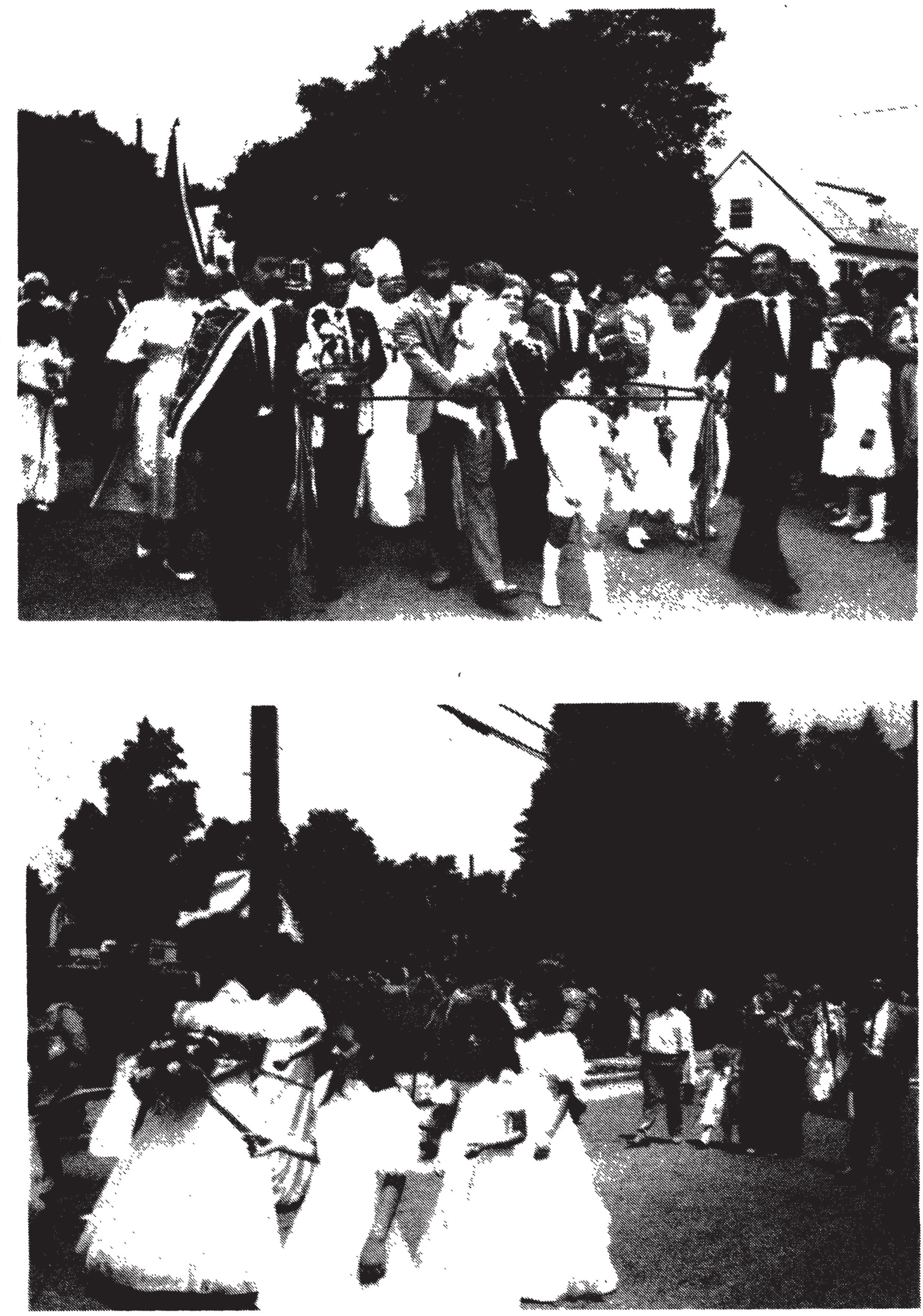

LÁM. II.-Fig. 1: La corona en procesión.-Fig. 2: Las «aias» en procesión. 

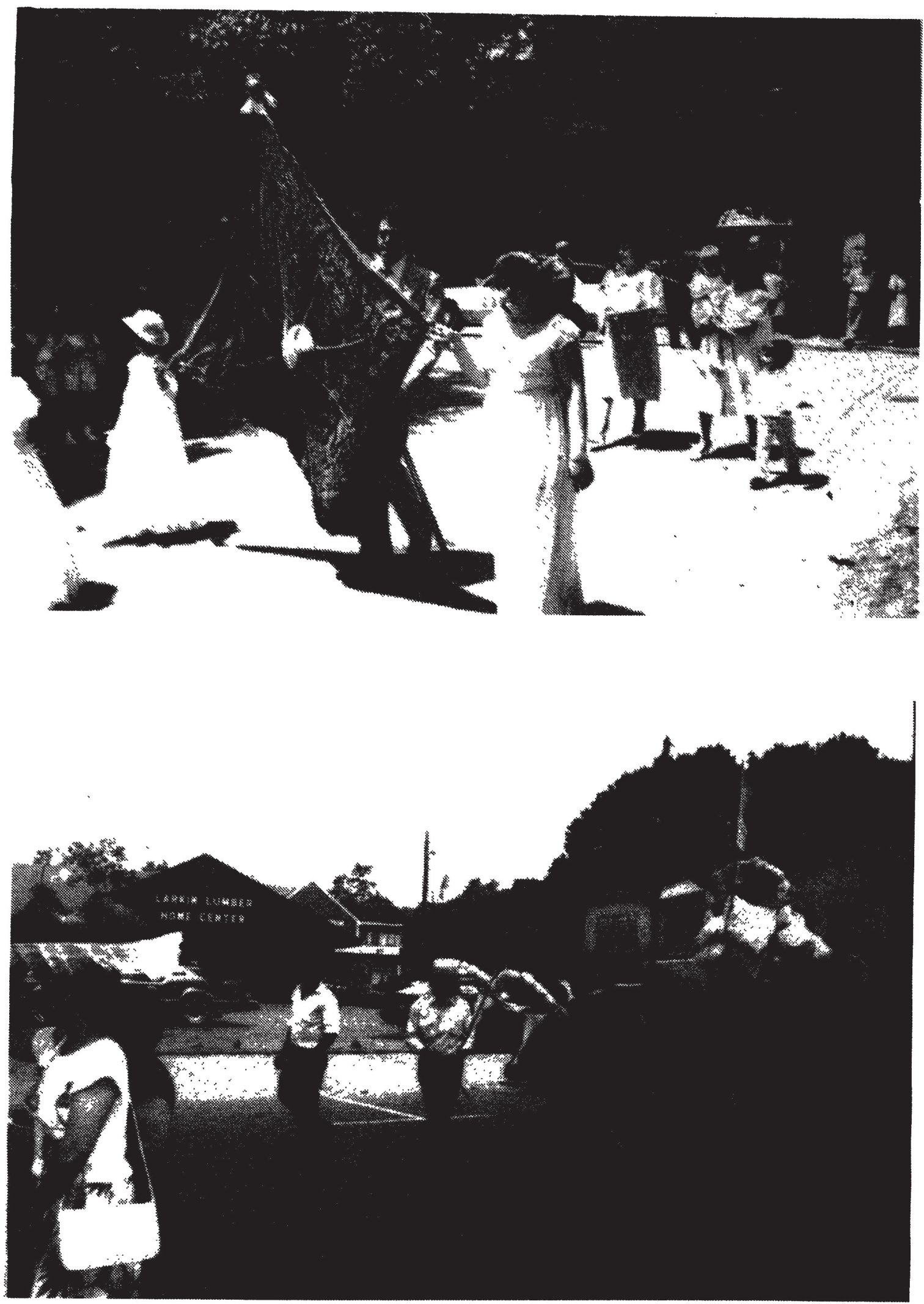

LÁM. III.-Fig. 1: Bandera del Espíritu Santo en procesión.-Fig. 2: Carro de bueyes en la procesión. 

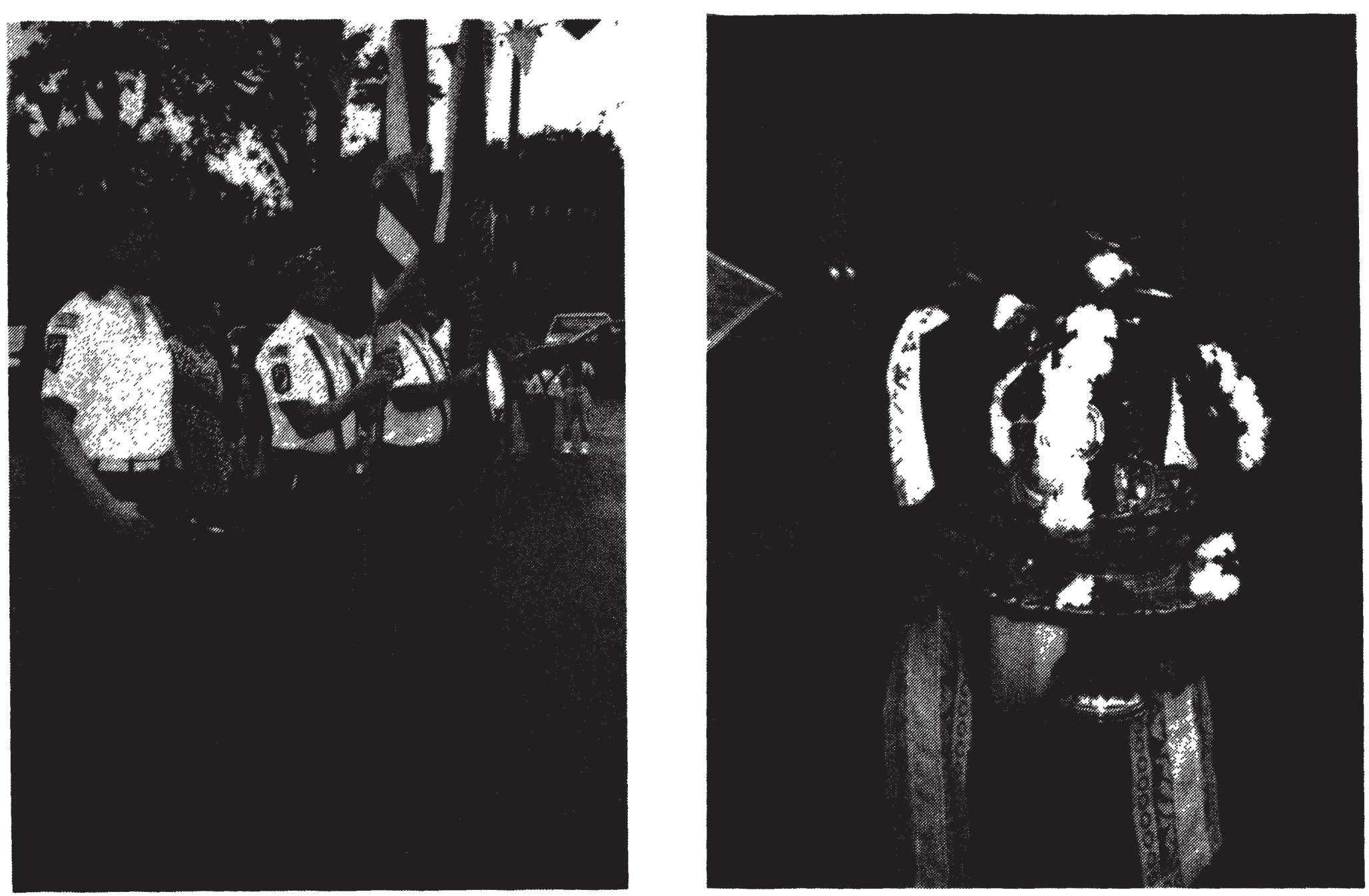

LÁM. IV.-Fig. 1: La legión americana forma parte del cortejo procesional.-Fig. 2: «Mordomo» con la corona. 


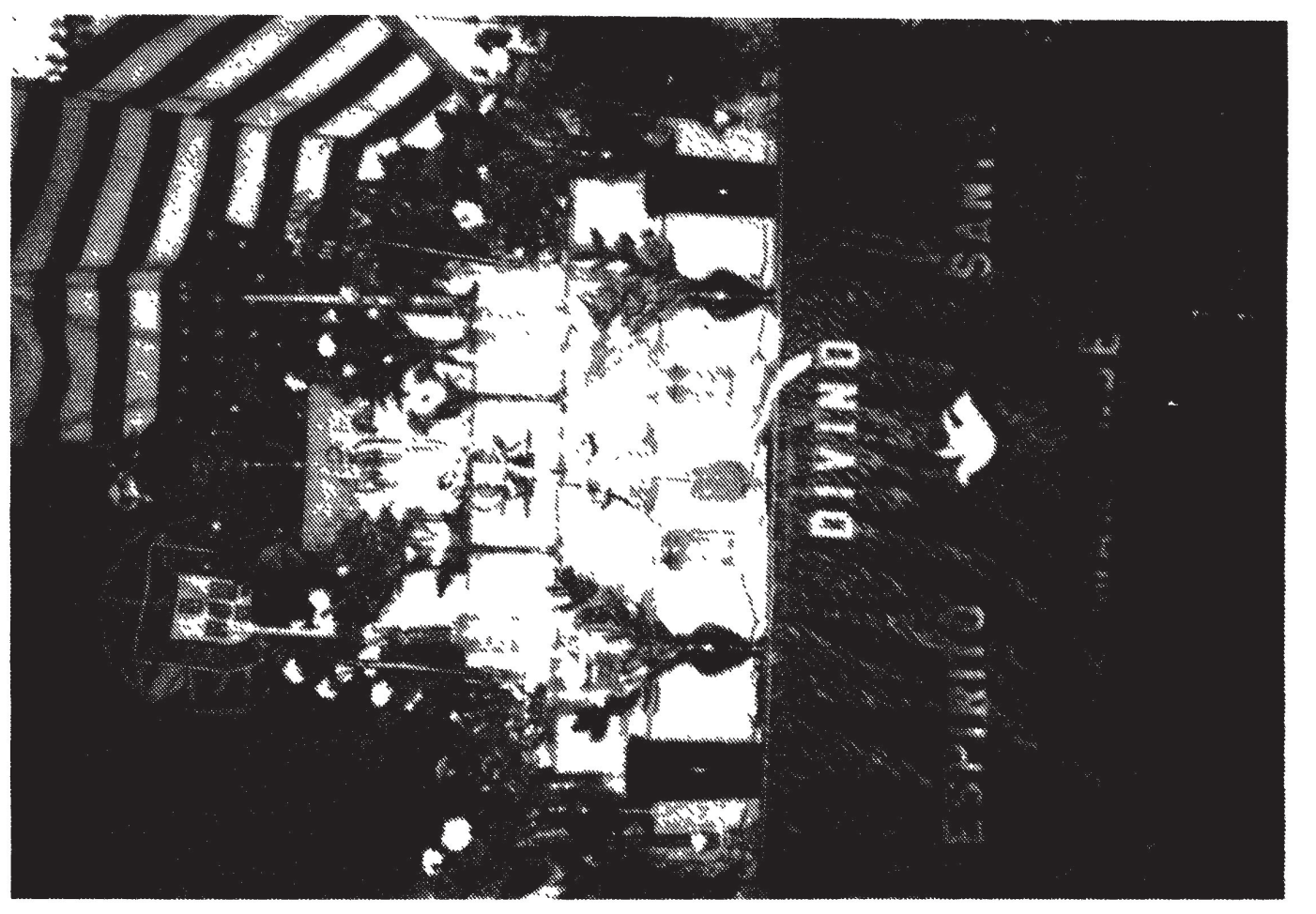



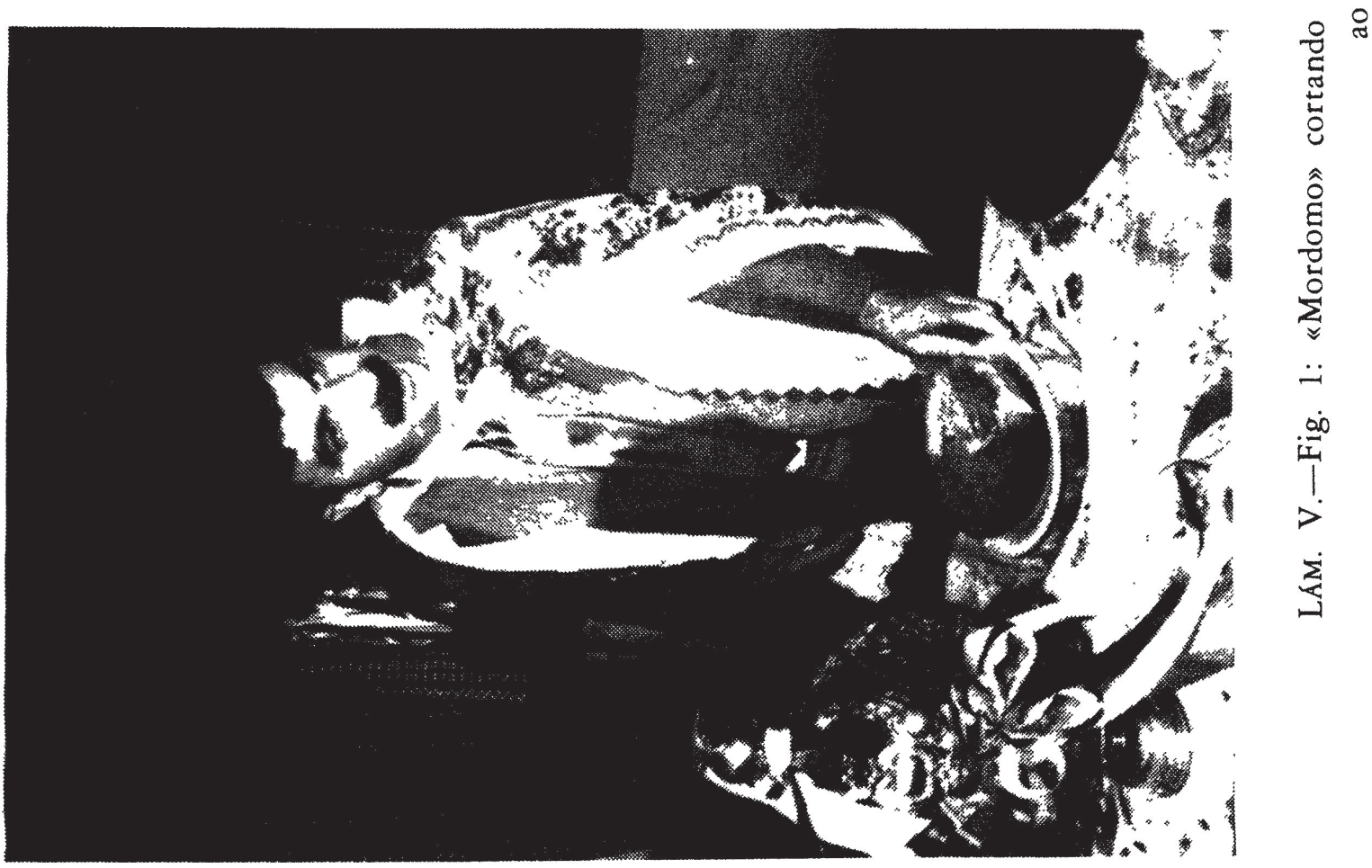



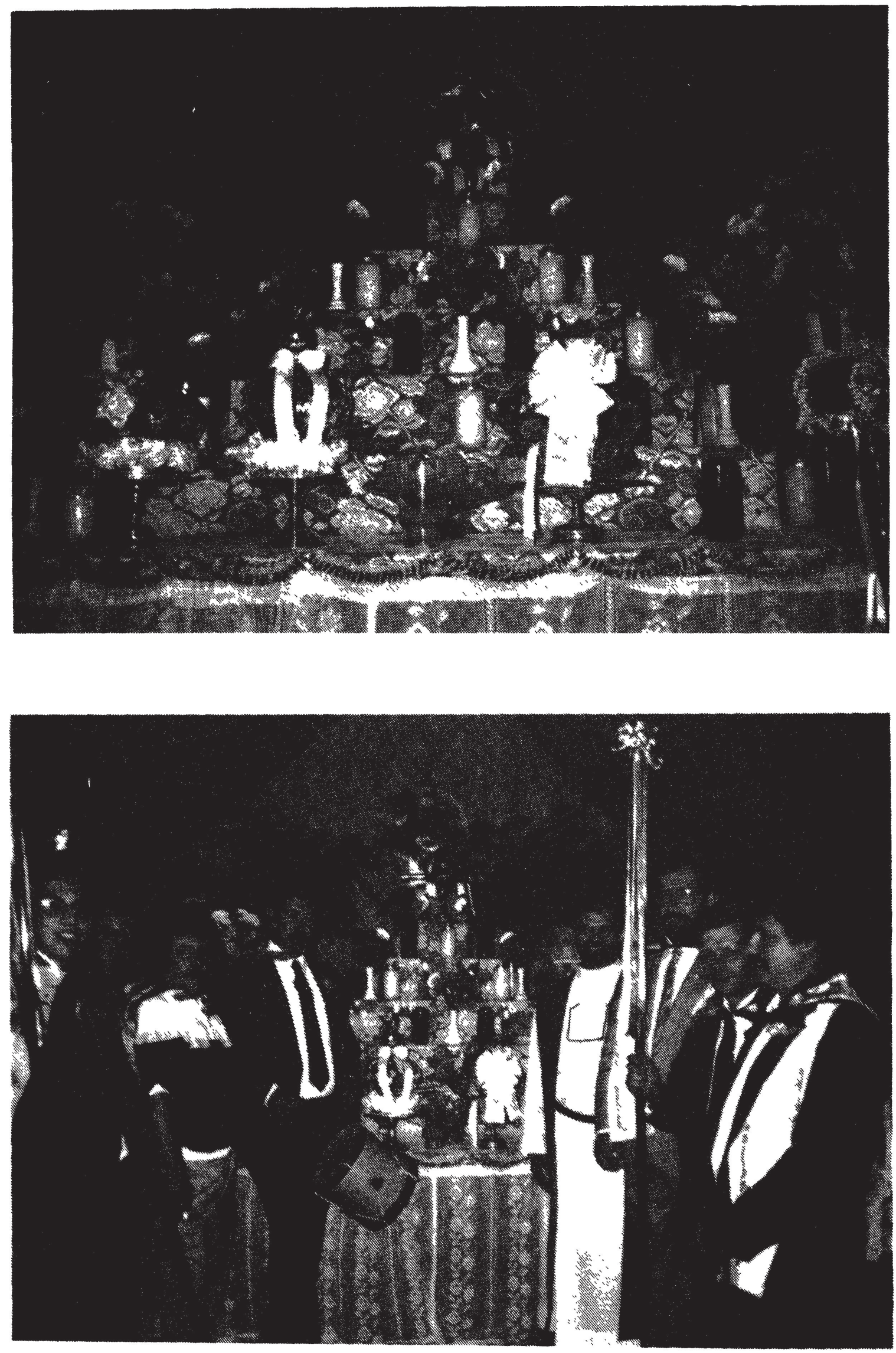

LÁm. VI.-Fig. 1: Altar con las coronas.-Fig. 2: El comité del Espíritu Santo ante el altar, en 1991. 